\title{
Preempting Racist and Transphobic Language in Student Writing and Discussion: A Review of Alex Kapitan's The Radical Copyeditor's Style Guide for Writing about Transgender People and Race Forward's Race Reporting Guide
}

\section{Nick Marsellas - University of Pittsburgh}

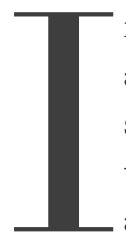

$\mathrm{n}$ almost all cases, we give students explicit instruction before asking them to perform a task. We model, give prompts, explain grammatical logics, etc. However, we often stumble when trying to prepare students to work with course readings or assignments that deal with race and gender. In many cases, instructors and students are nervous about students' potential to say something inappropriate or offensive, and the tangle of heightened emotion around socially just (or "politically correct") language makes actual learning difficult. Alex Kapitan's The Radical Copyeditor's Style Guide for Writing About Transgender People and the nonprofit racial justice organization Race Forward's Race Reporting Guide alleviate student anxieties by offering definitive, easy to understand language guidelines and the rhetorical logics behind those guidelines. These texts are an invaluable supplement to course materials that ask students to engage with race and gender. I will often assign these texts as their own reading assignment during the first week of class in order to establish classroom norms, and then I encourage students to refer back to the guides periodically as we work with other texts and assignments throughout the semester.

Kapitan's style guide, the title often shortened in my classroom to The Transgender Style Guide, helps students to see the political nuances inherent in the practice of writing. As Kapitan says, "Radical copyediting isn't about absolutes; it's about context and care." This helps students to reframe their understandings of writing through the lens of discursive power in ways that carry over into discussions of other writing decisions and style rules. The Race Reporting Guide offers a similar sentiment, saying, "Language matters, and we need more tools to move our race conversations forward in more accurate, fair, and productive ways" (i). Both of these style guides frame their grammatical and linguistic instruction through practices of care and relation to power systems rather than prescriptive correctness for the sake of prestige. Ultimately, these style guides remind us of the true purpose of writing instruction-to communicate clearly with our peers through the establishment of shared understandings of language.

After the introduction of their frameworks, the two style guides diverge in format. The Race Reporting Guide, initially meant to provide instruction to reporters as a supplement to The Associated Press Stylebook, offers the following sections: 1) guidelines for covering issues with a racial lens, 2) guidelines for writing about specific racial and ethnic groups, 3) harmful racial discourse practices, 4) key terms and concepts, and 5) online resources for further reading. I ask my students to read this 36-page guide in full before beginning writing, rather than using it as an intermittent reference for specific writing rules. I do this because many of the students using the guide have not cultivated a 
sense of careful attention to language around these issues like they have with grammatical concerns, and so they are less likely to actively seek out a reference for assistance. In the section "Seven Harmful Racial Discourse Practices," each of the practices is something common in white academic writing: practices like individualizing racism and prioritizing intent over impact. The guide then describes the effect of that practice on racial discourse and gives an example of the practice to help illustrate the point. Even though I have assigned supplementary theoretical texts that have tried to teach these lessons in the past, students have never shown as much growth over such a short period of time as they have when using this style guide. Students are quick to pick up the guide's linguistic/conceptual terms as a way of discussing race, and the guide helps set clear boundaries about what is and what is not up for debate, leading to richer collaborations and discussion with more active participation in class and less trepidation in students' writing.

The Transgender Style Guide offers a more familiar format to style guide readers-after the introduction, it is broken down into three major sections: 1 ) correct/current usage of transgenderrelated language, 2) bias-free and respectful language in reference to transgender people, and 3) sensitive and inclusive broader language. Each of these sections contains subsections, and each rule appearing in a subsection is accompanied by a paragraph or two of linguistic and cultural analysis, offering an explanation for why this rule would help the writer better align themselves with the style guide's goals of more inclusive and accurate writing. The guide is short enough to read in one sitting, and I advise my students to do so for the same reasons I ask them to read the Race Reporting Guide.

As a result of the guides being formatted as texts to be read front to back, students and I have had some difficulty navigating to specific rules quickly for reference. These texts are meant as supplementary style guides, and they therefore do not have the specificity of organization that the MLA or APA guides have. However, both of the guides reviewed here are available for free as digital texts, so using a computer's search feature became an easy workaround to this problem.

Although the guides are far more comprehensive than other language resources addressing similar topics, there are still moments where students have wanted to look to the guides for best practices only to realize that the writers had not given specific instruction for the writing situation the student was in. As pedagogical texts, however, this made the guides perhaps even more useful. Any "rules" that aren't in the style guides provide valuable opportunities for the class to discuss different motivations behind particular language choices, and ultimately to make a decision informed by the general instructions of the guides as well as the particular writing situation students are navigating.

Another outcome of assigning these style guides is more active engagement with discussions of social justice, particularly by students who have never had to discuss things like systemic racism, misogyny, or transphobia before. After a few weeks of using these style guides as the foundation for our language practices, students in my classroom have shared that they felt much less anxiety than when they discussed social justice issues in other classes. Having a set of guidelines at the outset alleviated much of their fear that various participants in a discussion were operating at different levels of "wokeness" and that one student's honest mistake would look to others like a deliberate act of linguistic violence.

Foregrounding these style guides has led to more expressions of curiosity and willingness to 
ask questions-it has become assumed that if the answer to a question about socially just language is not in one of these style guides, the entire class would benefit from discussing the question. In this way, these style guides become an integral part in establishing a shared foundation of race and gender literacy at the outset of the course. In the first week of class, a student asked whether the term "transsexual" was ever appropriate and what its relation was to the term "transgender." It's worth noting the achievement of even developing a classroom space where students have the beginning literacy and confidence to ask a question like this in the first week of class, let alone being able to offer them answers to these often-difficult questions. I gave a brief version of my own understanding, but I asked the class whether they could go back and find an answer in the resource. One student mentioned a link in the style guide to the supplemental article "I Was Recently Informed I'm Not a Transsexual" (Wilchins), and another student captured the ethos of the guide, saying that we should be able to hold the reality that people might have different preferences for describing their experiences.

The discussion of gender in the first week of class has been particularly helpful for introducing a nonbinary author later in the semester. Students in earlier classes where I introduced a nonbinary author had immense difficulty engaging the transgender author, greatly reducing their willingness to engage the text. There was an implicit sense in the room that students should use their words carefully, but without specific guidance, they were self-conscious and more prone to accidentally making transphobic comments. For example, students who have not learned rules like "avoid language that reduces people to their birth-assigned sex" were more prone to use "biologically male" or "biologically female" to indicate various aspects of a trans person's experience including their current genitals, their genitals at birth, the gender in which they were raised, their chromosomes but not their genitals, the fact that someone was trans at all (e.g., "she is a biological male" in place of "she is trans"). Not only is this type of language a harmful reduction of someone's experience, it is a terribly confusing amalgam of signifieds that results from our assumptions about the constancy of biological sex.

Likewise, since I've included the Race Reporting Guide in my course materials, students have been more able to explore themes of race as critique of systems rather than a matter of the individual author's opinion or experience. This stems both from explicit instruction from the style guide to "Investigate issues from a systemic ('Is there an institution or a practice at work that has race-based consequences?') over an individual ('Is this person a racist?') perspective," and from the overall priorities of the style guide (2). Students become less preoccupied by questions of self-purity when the focus becomes systemic, and while the analysis is more difficult, students of all backgrounds have responded more positively to systemic analysis than to individualist interpretation practices. This systemic analysis paves the way for students to see matters of language and matters of race as mutually reinforcing and interconnected. Students less frequently ask, "Why are we talking about race in a writing classroom?" when they have read this document, as they have been primed to understand questions of language as questions of power, prestige, and ultimately, race.

These style guides help students to see the connections between socially just language and the traditional writing skills they have been practicing and will continue to practice in any writing 
classroom. The Race Reporting Guide and The Radical Copyeditor's Style Guide for Writing About Transgender People are untapped resources for any classroom where gender or race may be a topic of discussion. By the end of the second week of class, my students are familiar enough with these style guides to talk (semi-)comfortably about issues of gender involving trans, cis, and nonbinary people and issues of race involving white people and people of color. These conversations will be difficult regardless, but the style guides presented here can offer important resources for making sure that the difficulty comes from intellectual growth rather than from the social discomfort around conversations of marginalization which so many students (and teachers) have been conditioned to feel. 


\section{WORKS CITED}

Kapitan, Alex. “The Radical Copyeditor's Style Guide for Writing About Transgender People." Radical Copyeditor, 21 Aug. 2017, radicalcopyeditor.com/2017/08/31/transgender-styleguide/. Accessed 17 Feb. 2020.

Race Forward: The Center for Racial Justice Innovation. Race Reporting Guide, version 1.1. Race Forward, June 2015, www.raceforward.org/reporting-guide. Accessed 17 Feb. 2020.

Wilchins, Riki. "I Was Recently Informed I'm Not a Transsexual." The Advocate, 7 June 2017, www. advocate.com/commentary/2017/6/07/i-was-recently-informed-im-not-transsexual. Accessed 17 Feb. 2020. 